\title{
JOURNAL.RU
}

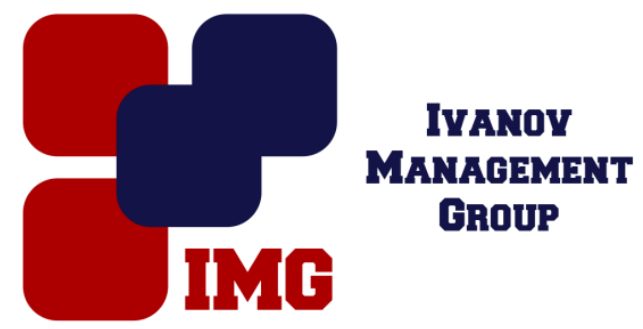

Данилов Д.С.

Саратовский Государственный Технический Университет имени Гагарина Ю.А. Саратов, Россия

doi: $10.18411 / \mathrm{lj}-30-06-2017-50$

idsp 000001:1j-30-06-2017-50

\section{Новые средства производства в архитектуре}

\section{Аннотация}

Процесс создания архитектурной формы разделён на два этапа: проектирование и производство. Соответственно этим этапам можно разделить средства, которые использует архитектор для решения задач на средства проектирования и средства производства. Средства производства являются одним из оснований архитектурной практики. Существует ряд архитектурных стилей, для которых появление новых средств производства имеет исключительно важное значение.

Ключевые слова: архитектура, архитектурный стиль, развитие архитектуры, средства производства, ЧПУ, параметризм

Процесс создания архитектурной формы разделён на два этапа: проектирование и производство. Соответственно этим этапам можно разделить средства, которые использует архитектор для решения задач на средства проектирования и средства производства.

Средства производства в архитектуре зависят в первую очередь от уровня развития техники. Долгий период развития новых средств производства сопряжен с большими масштабами архитектурных сооружений. Ещё большее время требуется для того, чтобы новые средства производства распространились повсеместно. В других областях дизайна новые средства производства начинают использоваться гораздо раньше и для архитекторов дизайн становится в 
некотором роде полигоном, на котором отрабатываются механизмы использования новых технологий.

Средства проектирования и средства производства ограничивают и обуславливают друг друга, например, без соответствующих средств производства некоторые средства проектирования могут быть неприменимы, возможна и обратная ситуация.

Не каждый сдвиг в области техники отражается на архитектуре, однако в ряде случаев такая взаимосвязь существует,нас же в первую очередь интересует кардинальные сдвиги в области техники, влияющие на формирование архитектурных стилей.Существует ряд стилей, для которых появление новых средств проектирования или производства имеют исключительно важное значение.

Итак, на протяжении рассматриваемого периода можно выделить три основныепарадигмы в сфере производства: доиндустриальная модель - большое разнообразие в малых количествах, индустриальная (фордистская) модель малое разнообразие в больших количествах, постиндустриальная (постфордистская) модель - большое разнообразие в больших количествах.

C начала истории западноевропейской архитектуры до начала индустриальной цивилизации средства производства развивались по курсу совершенствования способов обработки материала.Сравнив производство романской архитектуры, и, например, архитектуры эпохи классицизма мы не увидим принципиальной разницы, за исключением уровня обработки материалов и совершенства строительных конструкции. Последнее скорее связано с развитием инженерной мысли, чем с совершенствованием средств производства. До начала двадцатого века тип производства в архитектуре не изменялся - доиндустриальная модель - единичное или серийное производство.

Первым действительно важным переломным моментом можно считать индустриальную революцию в технике. $\mathrm{C}$ началом $\mathrm{XX}$. появился принципиально новая парадигма в технике - массовое производство. Парадигма массового производства стала определяющей для всей эпохи, в том числе и для архитектуры модернизма. Идея массового производства - это не просто тип производственных отношений, это парадигма мышления. Для общества в целом идея массового производства выразилась через идею «общества всеобщего благоденствия», для архитектуры в модернизме.Факторы, определяемые, логикой самой модели производства вызвали необходимость разработки типовых конструктивных решений, начиная с дверной ручки и заканчивая 
градостроительным уровнем. Рациональная сторона архитектуры выражена в архитектуре модернизма в абсолютной форме. Новый метод производства, типовые предварительно изготовленные конструкции, новые строительные материалы - всё это послужило отправной точкой для архитектуры первой половины двадцатого столетия.

Средства производства не привязаны к какому-то конкретному стилю, но одновременно с этим могут направлять развитие стиля, задавать определённые рамки формообразования. Так модель массового производства не является тем, что определяет все стороны архитектуры модернизма. Ничто не мешает применить средства массового производства к другим стилям. Во второй половине - конце ХХв. модель массового производства занимала доминирующую позицию и продолжала обслуживать архитектуру постмодернизма не менее успешно, чем архитектуру модернизма. Однако несомненно, что модернизм не стал бы тем, что он есть без парадигмы массового производства.

Следующий переломный момент в развитии технологий - переход от фордистской модели производства к пост-фордистской. Коротко суть этого перехода можно описать так: вместо массового производства одинаковых изделий, массовое производства индивидуальных изделий. Конечно этот процесс не был спонтанным, можно сказать, что он начался практически сразу после зарождения фордизма.

Ярким примером перехода от индустриальной модели производства к постиндустриальной является сам проект Генри Форда - модель «Т». Спустя 19 лет после того как его автомобиль завоевал рынок, его концепция всё же исчерпала себя и в 1927 году его самый популярный автомобиль был снят с производства. Несмотря на все плюсы модели Т, она перестала устраивать потребителя, особенно если учесть, что автомобиль в течении 10 лет выпускалась только в чёрном цвете. Спустя время появился более широкий спектр предложений, и касательно всего сегмента автомобильной промышленности, и разнообразия модельного ряда внутри отдельного предприятия. Идея «общества всеобщего благоденствия» даже на этом примере показывает свою несостоятельность. Удешевление предметов промышленного производства, сокращение цикла потребления товаров, разнообразие дизайна признаки постиндустриального общества и следствие перехода к постфордистской модели производства. 
В рамках естественной эволюции индустриальной модели производства, технологии становятся всё более гибкими. В архитектуре мы можем проследить тот же процесс, архитектура постмодернизма является началом перехода от индустриальной модели производства к постиндустриальной. В архитектуре этот период отражается, помимо прочего, в большей вариативности форм.

Первые предпосылки пост-фодрдистской модели появились задолго до двадцатого века. В 1804 году был изобретён ткацкий станок с возможностью перепрограммирования с помощью перфокарт, такой станок можно считать праотцом современных станков с ЧПУ (Числовое Программное Управление). Однако до появления компьютеров, такие станки были эффективны только в полмеры, их перепрограммирование было слишком трудоёмким. Но «цифровая революция〉 снабдила уже давно существовавший инструмент новым, гибким средством программирования. Компьютер являясь новым средством проектирования в архитектуре, стал также основой нового средства производства.

Относительно воздействия на архитектуру переход к постфордистской модели не менее грандиозен, чем переход к фордистской. Если перенос архитектуры модернизма на доиндустриальную модель производства ещё можно представить, то с параметрической архитектурой это просто невозможно. Параметризм - новейший архитектурный стиль, провозглашённый Патриком Шумахером, идеи параметризма наиболее полно раскрыты в его основном труде “The Autopoiesisofarchitecture" [1,2].Новые технологии производства были недостающим звеном для возникновения параметрической архитектуры, как только этот пробел был закрыт цифровые авангардные эксперименты перешли в область реального строительства. Благодаря совершенствованию станков с ЧПУ и появлению гибкого средства их программирования, новым средствам параметрического проектирования, CAD и BIM системам, новая модель производства практически полностью сформировалась в архитектуре. Для архитектуры это выражается, например, в том, что воплощение какой-либо конструкции из уникальных элементов, не отразится ни на удорожании и усложнении производства (на предприятии работающего в рамках постфордистской парадигмы), ни на усложнении сборки. Такая модель производства даёт архитектору широчайший спектр, ранее недоступных, возможностей со стороны формообразования, возможностей реализации наиболее подходящих форм вне зависимости от их сложности. Воплощение эстетических принципов нового стиля было бы просто невозможным, или крайне нецелесообразным, без 
соответствующих средств производства, среди которых с некоторыми условностями можно выделить следующие виды:

Станки с ЧПУтакие станки существуют уже не один десяток лет, но ранее не существовало достаточно гибкого средства их программирования. Область применения станков с ЧПУ в строительстве: раскрой различных типов материала, 3д-фрезеровка, изготовления матриц и т.д. Такие станки позволяют создавать оболочки любой сложности, из плоских или криволинейных элементов, так же активно используются при созданиипредметов дизайна.

3Д принтерыуже начинают, в качестве эксперимента, применятся в строительстве. Это мощнейший инструмент производства, который несомненно будет широко применятся в архитектуре. 3Д принтеры позволяют создавать формы любой сложности. В последнее время появляются крупномасштабные $3 д$ принтеры способные печать здания, ведутся разработкив области печати несколькими материалами разными по свойствам (например, материалы поразному работающие на растяжение и сжатие), разработки в области печати металлом, что необходимо в архитектуре. Для наступления эры 3Д принтеров нужны новые достижения в области строительной химии, но принтеры ужесейчас появятся на строительных площадках.

Робототехника - универсальный инструмент производства, сфера применения которого ограничена лишь фантазией и экономической целесообразностью, от производства до финишной доработки изделий и сборки. Роботов применяют при изготовлении сложных форм, при покраске, полировке, сварке и т.д. Архитекторы взяли на вооружение промышленных роботов, которые использовались ранее, например, в области автомобилестроения. Сфера применения промышленных роботов постоянно расширяется благодаря большой гибкости их использования. Многие передовые архитекторы и университеты активно экспериментируют с применением таких роботов.

Существует ещё множество инструментов, которые призваны решать частные задачи производства, здесьони не были указаны ввиду их узкой специализации. Новые средства производства открывают перед архитектором широчайшие возможности в области формообразования. Новый архитектурный стиль - параметризм, полностью основан на новых инструментах производства и проектирования, и без них невозможен. 
1. Schumacher, P. The Autopoiesis of architecture, vol.1, A new framework for architecture. [Аутопоэзисархитектуры.T.1.] United Kingdom, London: Willey \& Sons. 2011 - 498c.

2. Schumacher, P. The Autopoiesis of architecture, vol.2, A new agenda for architecture. [Аутопоэзисархитектуры.T.2.] United Kingdom, London: Willey \& Sons. 2012 - 715c. 